\title{
AUTONOMIA PRIVADA E REGULAÇÃO ESTATAL: UMA REFLEXÃO SOBRE A ATUAÇÃO DO ESTADO NA REGULAMENTAÇÃO DOS PRODUTOS DERIVADOS DE TABACO
}

\author{
PRIVATE AUTONOMY AND REGULATORY STATE: A REFLECTION ON THE \\ PERFORMANCE OF STATE IN THE REGULATIONS OF TOBACCO PRODUCTS
}

\author{
Wesllay Carlos Ribeiro ${ }^{1}$ \\ Renata Siqueira Julioº
}

\section{Resumo}

A autonomia encontra uma aporia na questão da opção pelo uso do tabaco e a regulamentação pelo Estado. Este estudo analisa a atuação do Estado, pós CRFB/88, por meio da ANVISA, na regulamentação da presença de Nicotina nos produtos derivados de tabaco. Trata-se de uma pesquisa exploratória e descritiva, com procedimento bibliográfico e documental. O cigarro tem mais de 4.720 substâncias, dessas a nicotina é a causadora da dependência. A atuação do Estado se restringe ao reconhecimento dos danos causados pelo tabaco. Não foram encontradas normas que vedem a presença de nicotina no cigarro.

Palavras-chave: Autonomia Privada; Nicotina; ANVISA; Atuação do Estado.

\section{INTRODUÇÃO}

A sistemática constitucional vigente tem como pano de fundo o respeito à liberdade da pessoa em suas relações com o Estado e com outros particulares. Também atribui ao Estado uma função complexa colocando-o na posição de devedor de prestações positivas e negativas, objetivando sempre a proteção da pessoa como fim do Direito. A autonomia da pessoa encontra uma aporia quando posta a questão da opção pelo uso do tabaco e a atuação do Estado na regulamentação do setor tabagista, especialmente em razão da tradição jurisprudencial de nosso país, arraigada ao entendimento que a pessoa tem o direito de optar por fumar ou não, e o debate jurídico científico sobre os males derivados do uso do tabaco causados a pessoa e a sociedade.

\footnotetext{
1 Professor da Universidade Federal de Alfenas das disciplinas de Direito Privado. Possui graduação em Direito pela Faculdade de Direito de Varginha (2001), especialista em Direito Público pela UNIGRANRIO (2004), mestre em Direito pela Universidade Estácio de Sá (2009) e doutorando em direito pela Pontifícia Universidade Católica de Minas Gerais (2010). Tem experiência na área de Direito, com ênfase em Direito Civil, atuando principalmente nos seguintes temas: constituição e direito civil, direitos fundamentais e direitos da personalidade, responsabilidade civil e administração.

2 Mestre em Pesquisa Clínica em Doenças Infecciosas pelo Instituto de Pesquisa Clínica Evandro Chagas da Fundação Oswaldo Cruz (FIOCRUZ); Graduação e Licenciatura em Enfermagem pela Universidade Federal de Juiz de Fora (2005). Especialização em Geriatria e Gerontologia Interdisciplinar pela Faculdade Estácio de Sá de Juiz de Fora. Concentra sua atuação nas áreas de epidemiologia e HIV/Aids.
} 
O tabaco encontra a sua forma mais popular de comércio no cigarro, produto que contém milhares de substâncias em sua composição, muitas delas originárias da própria planta, algumas decorrentes do processo de fabricação e outras inseridas pela indústria fumígena. Dentre essas substâncias a Nicotina é considerada a responsável pela dependência química e física dos milhões de usuários dos produtos derivados de tabaco. Neste sentido temos uma aparente contradição ligada à garantia constitucional da liberdade e a utilização de um produto, que por suas características farmacocinéticas, mitiga a autonomia da pessoa.

Destarte levando em consideração a atual sistemática constitucional o presente estudo pretende analisar como se dá a atuação do Estado, pós CRFB/88, por meio da ANVISA, na regulamentação da presença de Nicotina nos produtos derivados de tabaco? Para tanto o presente estudo objetiva examinar a relação entre o uso de tabaco e a dependência química e física a nicotina; Perscrutar a proteção constitucional a autonomia como direito da pessoa se autodeterminar; e investigar as normas da ANVISA que regulam o setor tabagista.

O trabalho se justifica pelo cunho acadêmico, tendo em vista a pouca produção jurídica científica sobre o tema. Também desperta interesse pela grande importância econômica do setor que gera emprego e renda, bem como pela carga tributária que é originária da atividade. É também relevante do ponto de vista social, haja vista os danos à saúde que decorrem da atividade e os impactos que causam nas contas e nos investimento em saúde pública. Além disso, o estudo se justifica pela importância que a autonomia privada, considerada como elemento do princípio da dignidade da pessoa humana, representa na atual sistema jurídico constitucional, pois como assinala Clève (2009) no direito constitucional contemporâneo existem duas correntes doutrinárias: a dogmática da razão do Estado, que assume uma visão positivista do Direito e leva em consideração apenas a dimensão política do Direito Constitucional, e a dogmática constitucional emancipatória, que busca o Direito como efetivação da dignidade da pessoa humana e que se realiza por meio da aplicação dos princípios na realidade existencial.

O artigo está estruturado da seguinte forma: inicialmente, é apresentada a introdução seguida da revisão bibliográfica, na qual, são abordados os temas: tabaco e dependência a Nicotina; proteção constitucional da autonomia; e por fim são apresentados: a metodologia; a discussão de resultados e as considerações finais.

\section{TABACO E DEPENDÊNCIA A NICOTINA}

Segundo Delfino(2002) o tabaco é originário da América Central e seu descobrimento se deu no ano de 1000 a.C. e era usado pelos índios em rituais religiosos que buscavam 
proteger e purificar os guerreiros. Ainda segundo o mesmo autor a disseminação da erva na Europa ocorreu a partir do século XVI e se deve a um diplomata francês chamado Jean Nicot, que acabou tendo seu nome utilizado na nomenclatura científica do produto: nicotiana tabacum.

Naquele tempo o seu uso foi associado, por médicos, a perda da virilidade e sua utilização proibida, sendo cominadas graves penas para a desobediência. Entretanto, a sanção ao uso do tabaco não foi suficiente para coibir o consumo e o produto se alastrou pela Europa e mais tarde por todo o mundo. Com a impossibilidade de coibir o uso do tabaco optou-se por legalizá-lo e com a pretensão de diminuir o consumo passou-se a tributá-lo fortemente, entretanto, como os malefícios do uso tardavam a aparecerem, os governos acabaram por admitir o seu comércio, amparados na premissa que a indústria fumígena trazia os benefícios da geração de emprego e renda.

O produto mais popular e principal forma de disseminação do tabaco é o cigarro. Atualmente onze sociedades empresárias encontram-se registradas e autorizadas, pela ANVISA(2010a), a comercializar o produto no País: American Blend Importação, Exportação, Indústria \& Comércio de Tabacos Ltda., Cia Sulamericana de Tabacos S/A; Cibahia Tabacos Especiais Ltda.; Ficet Indústria e Comércio de Cigarros Importação e Exportação Ltda.; Golden Leaf Tobacco Ltda.; Indústria e Comércio Rei Ltda.; Itaba Indústria e Comércio Brasileiro Ltda.; Philip Morris Brasil; Phoenix Indústria e Comércio de Tabacos Ltda.; Real Tabacos Ltda.; e Souza Cruz S.A.. Essa última detém mais de 60\% do mercado no País.

O cigarro conta com "mais de 4.720 substâncias presentes na fumaça do cigarro industrializado. De todas estas substâncias, a nicotina é reconhecida como sendo a causadora da dependência" (SALGADO, 2002, p.25). O cigarro se divide em etapas: gasosa e particulada. Segundo Delfino (2002, p. 6) a "fase gasosa é composta de substâncias, tais como monóxido de carbono, cetonas, formaldeídos, acetaldeído e acroleína” e a fase particulada composta pela nicotina e pelo alcatrão que concentram "quarenta e três substâncias cancerígenas, podendo-se citar como exemplos o arsênico, níquel, benzopireno, cádmio, chumbo, além de substâncias radioativas, como o polônio 210, o carbono 14, radio 226, radio 228 e potássio $40 . "$

Algumas substâncias presentes no cigarro são próprias do tabaco, outras decorrentes do processo de industrialização e cerca 600 substâncias são aditivadas pela indústria com a intenção de torná-lo mais palatável, bem como objetivando maior liberação de nicotina. Entre os aditivos que tem a função de liberar mais nicotina está à amônia que é usada pura ou na 
forma de fosfato de diamônia (DAP) ou hidróxido de amônia. A amônia tem a função de elevar o pH da nicotina aumentando sua liberação, permitindo uma maior difusão no organismo e maior penetração pelas membranas celulares dos tecidos. Com o aumento do $\mathrm{pH}$ a nicotina fica mais tempo no organismo "porque é mais facilmente reabsorvida pelos túbulos renais, diminuindo sua eliminação, e com isso eleva-se sua concentração sanguínea. Com esse processo, eleva-se a nicotino-dependência, como se disse, tornando o tabagista escravo do cigarro.” (ROSEMBERG, 2003, p. 11). Cabe salientar que a inclusão de amônia é prática corrente no processo industrial do tabaco.

O potencial viciogênico da nicotina é extremamente alto, oitenta por cento, e superior ao de muitas drogas ilícitas como demonstra o gráfico 1 elaborado com dados do National Institute on Druge Abuse, órgão do Departamento de Saúde dos Estados Unidos da América, e citado por Salgado (2002) para tratar a dependência a nicotina.

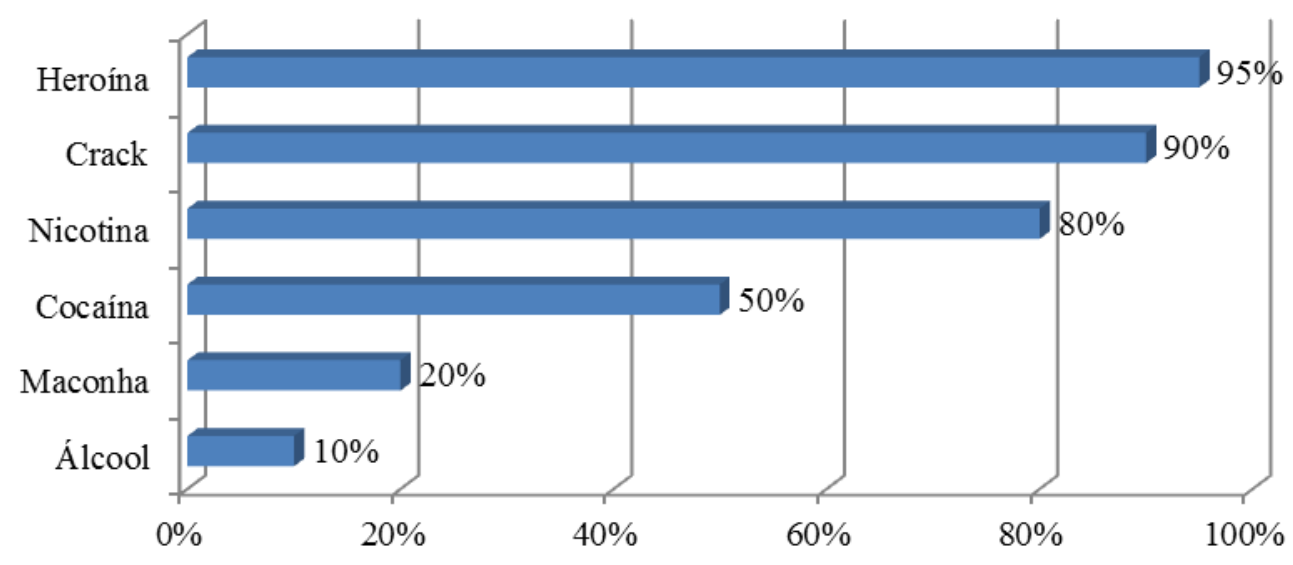

Gráfico 1 - Potencial viciogênico das drogas de abuso

Fonte: Adaptado de SALGADO, 2002, p. 26

Segundo dados do National Institute on Drug Abuse (2010), a dependência ao cigarro é causada pela nicotina. Estudos publicados pelo referido Instituto demonstram que daqueles que tentam interromper o uso do tabaco, cerca de $85 \%$, em menos de uma semana retornam ao uso do cigarro e não conseguem parar de fumar. Esses mesmos estudos demonstram que a Nicotina atua sobre o cérebro ativando os circuitos que regulam os sentimentos relacionados ao prazer (áreas de recompensa). As pesquisas demonstram, ainda, que a nicotina aumenta os níveis de dopamina na área de recompensa, causando sensação similar ao que ocorre no uso de outras drogas como a cocaína, por exemplo, levando ao vício pela exposição continuada a 
Nicotina. Os efeitos farmacocinéticos da Nicotina contribuem para a dependência, pois quando se fuma, a Nicotina chega ao cérebro nos primeiros 10 segundos após a tragada, levando a sensação de prazer, que é interrompida também rapidamente, fazendo com que o usuário tenha que fumar várias vezes por dia para manter a sensação de prazer e evitar os sintomas da síndrome de abstinência, que incluem: irritabilidade, um forte desejo de fumar (craving ou fissura), déficit cognitivo e de atenção, perturbação do sono e aumento de apetite. Os efeitos da síndrome de abstinência começam poucas horas depois de interrompida a exposição à Nicotina, chegando ao seu ponto máximo em alguns dias, podendo durar semanas e até meses.

O fator dependência aliada à ausência de informações sobre os males do tabaco e décadas de propagandas que relacionavam o seu uso a status social, esportes e uma vida saudável criaram gerações de dependentes à nicotina e com isso o consumo de cigarro alcança, hoje, de forma generalizada todas as faixas etárias conforme demonstra a tabela 1 elaborada pelo IBGE (2009) e que ilustra o percentual das pessoas de 15 anos ou mais de idade usuários de tabaco fumado, por grupos de idade, segundo as Grandes Regiões do País no ano de 2008.

\begin{tabular}{|c|c|c|c|c|c|}
\hline \multirow{3}{*}{$\begin{array}{l}\text { Grandes } \\
\text { Regiões }\end{array}$} & \multicolumn{5}{|c|}{$\begin{array}{l}\text { Percentual das pessoas de } 15 \text { anos ou mais de idade usuários de tabaco } \\
\text { fumado }(\%)\end{array}$} \\
\hline & \multicolumn{3}{|c|}{ Grupos de idade } & \multirow[b]{2}{*}{35 a 64 anos } & \multirow[b]{2}{*}{65 anos ou mais } \\
\hline & Total & 15 a 24 anos & 25 a 44 anos & & \\
\hline Brasil & 17,2 & 10,7 & 18,3 & 22,7 & 12,9 \\
\hline Norte & 16,8 & 10,5 & 18,0 & 21,6 & 18,2 \\
\hline Nordeste & 17,2 & 9,5 & 17,0 & 24,7 & 19,4 \\
\hline Sudeste & 16,7 & 10,8 & 18,1 & 22,1 & 8,6 \\
\hline Sul & 19,0 & 12,6 & 21,6 & 23,0 & 13,0 \\
\hline Centro-Oeste & 16,6 & 12,0 & 17,8 & 20,6 & 11,6 \\
\hline
\end{tabular}

Como se pode notar mais de $17 \%$ da população do País fuma, sendo que esse percentual varia de grupo de idade, mas mantém uma constância durante toda a expectativa de vida da pessoa. Atualmente a OMS entende que o tabagismo é uma pandemia e classifica a dependência ao tabaco como doença mental e desordem de comportamento com indicação no Código Internacional de Doenças - CID pelo código: F17(WHO, 1993). A nicotina, considerado em estudos científicos como um psicotrópico (DELFINO, 2004), "figura entre as 
drogas de maior poder gerador de dependência. Se aliarmos a isso, o fato de que é uma droga aceita e disponível, temos uma mistura explosiva, que transforma o tabaco na maior causa evitável de mortes em todo o mundo." (SALGADO, 2002, p. 25).

O consumo de um produto com tantas substâncias nocivas além de gerar danos a pessoa, também restringe a sua liberdade, vez que a droga, devido à dependência, restringe e mitiga o exercício da autonomia privada.

\section{PROTEÇÃO CONSTITUCIONAL DA AUTONOMIA}

A dogmática constitucional emancipatória (CLEVÈ, 2009) busca no Direito a efetivação da dignidade da pessoa humana e se realiza por meio da aplicação dos princípios na realidade existencial.

O conceito moderno de dignidade humana encontra os seus primeiros passos na doutrina cristã (COMPARATO, 2008) e no pensamento clássico. Tanto no antigo como no novo testamento é possível encontrar referência de que o homem foi criado à imagem e semelhança de Deus (SARLET, 2007), daí o pensamento de São Tomás de Aquino(MORAES, 2007) entender que a dignidade é inerente ao homem. Segundo Moraes(2003, p. 53), a expressão dignidade vem do latim dignus que significa "aquele que merece estima e honra, aquele que é importante" e sua utilização sempre correspondeu à espécie humana.

Cabe, dessa forma, fazer referência à obra de Arendt(2008) que propõe uma resignificação do homem frente à pós-modernidade, para ela existe uma complicação própria do ser humano de se definir porque sempre que se pensa em 'alguém' (outro ser humano), inevitavelmente vem ao pensamento 'o que' esse alguém é, qual o seu status social, esquecendo o que existe de singular e específico na própria essência humana.

A Kant (MARQUES FILHO, 2004) é atribuído o processo de secularização da dignidade, que é transportada da noção do sagrado para ser construída em bases racionais. Segundo Sarlet (2007), Kant assinala que a autonomia da vontade, assim entendida como a possibilidade de autodeterminação em conformidade com as leis, é uma característica da razão que impera apenas nos seres humanos, o que constitui o fundamento da dignidade humana.

É do pensamento Kantiano (KANT, 2005, p.40) a chamada lei fundamental da razão prática pura, baseada no imperativo: "age de tal modo que a máxima de tua vontade possa valer sempre como princípio de uma legislação universal.” Destarte, o dever não está em 
conteúdos pré fixados, mas sim configurados em uma forma de vida relacionada a uma força universal e incondicionada, que para Kant era a moral.

Para Moraes (2003), o imperativo categórico de Kant impõe a exigência de que o homem nunca seja visto como meio para alguma finalidade ou objetivo, mas sempre como um fim em si mesmo. A esse respeito, a premissa é a de que os seres racionais, por natureza, são fins em si; portanto, um valor absoluto. Qualquer ser humano, por ser racional, representa a sua própria existência. Assim, resulta do imperativo Kantiano a necessidade de obediência das leis e o respeito mútuo (SILVA, 2007). Sarlet (2007) afirma, ainda, que, na visão de Kant, tudo tem um preço ou uma dignidade: assim teria um preço aquilo que pode ser substituído por equivalente, enquanto que o que não admite equivalente teria uma dignidade. Destarte, o homem, como ser único e inigualável, nunca teria um preço, mas sempre teria dignidade.

Seria, na visão de Kant (2005), uma 'revolução copernicana', alterando o sentido da natureza do conhecimento, de forma que, ao invés do homem girar em torno dos objetos, esses é que deveriam girar ao redor do homem. Tal visão, adotada nas principais teorias sobre dignidade humana (SARLET, 2007), constitui o ponto nodal da completa negação da coisificação do homem, adotado pela Constituição da República Federativa do Brasil de 1988.

A atual concepção de dignidade humana significa uma aplicação real e imediata do princípio como norma criadora e protetora de direito no mundo fático (JACHINTO, 2006) com aplicação efetiva e direta na realidade das pessoas.

Nesse sentido, uma das dimensões da dignidade se relaciona com a questão ontológica, aceita desde a época clássica, ao postular que a dignidade é qualidade intrínseca (SARLET, 2007) e irrenunciável do ser humano e, por isso, faz parte da essência da espécie humana, não se podendo ganhar ou perdê-la. Não se trata de algo que se pode pedir a alguém; também e certamente não é algo perecível ou que pode variar de grau durante a vida, de forma que, em certos momentos, a pessoa tenha mais ou menos dignidade de acordo com a sua própria percepção, idade ou estado mental. A dignidade é algo imutável e perene, inerente à vida humana. Embora não possa ser perdida ou ganhada, é certo que pode ser violada e, portanto, deve ser protegida. Por tal razão, Sarlet (2007, p. 67) afirma que "a dignidade evidentemente não existe apenas onde é reconhecida pelo Direito e na medida que este a reconhece, já que constitui dado prévio, no sentido de preexistente e anterior a toda experiência especulativa".

A evolução da premissa ontológica da dimensão da dignidade humana reforça a compreensão que ainda é considerada a noção Kantiana, que, por sua vez, tem na autonomia e no direito de autodeterminação de cada pessoa o seu fundamento. Em outras palavras, a 
capacidade que todo ser humano tem de se autodeterminar, de dizer e decidir sobre a sua própria conduta, sem que isso dependa da realização efetiva no mundo (COMPARATO, 2001). Decorre daí que todo ser humano tem igual dignidade, pouco importando se ele tenha ou não percepção da mesma. Encontra-se, pois, ligada à condição humana de cada indivíduo e não ao discernimento da pessoa (SARLET, 2007).

Além dessa concepção ontológica da dignidade humana, o homem deve ser pensado e analisado em sua intensa relação com outros seres humanos, como ser que vive em sociedade (COMPARATO, 2001). Assim, é possível falar também de uma dignidade que se dá em uma concepção intersubjetiva vez que por "sermos todos iguais em dignidade e direitos, o que fatalmente nos obriga a exercer o direito à dignidade de forma inter-relacional, respeitandonos na medida em que a igualdade torna-nos todos titulares de um mesmo direito" (JACHINTO, 2006, p. 79).

Sarlet (2007) salienta a dimensão intersubjetiva da dignidade parte da situação básica da pessoa em suas relações com os demais seres humanos ao invés de considerar o indivíduo. Entretanto, adverte que não significa que se possa sacrificar a dignidade de determinada pessoa em prol da comunidade, já que esta dimensão da dignidade importaria em uma obrigação geral de respeito pela pessoa, gerando uma gama de direitos e deveres mútuos em favor do próprio ser humano. Essa visão 'comunitária' da dignidade se operará também na relação dos indivíduos com o Estado, gerando, por sua vez, uma dimensão política da dignidade. Desse modo, cada um e todos passam a ser credores e devedores de uma igual proteção perante o Estado.

Ainda, segundo Sarlet(2007), a dignidade tem dupla dimensão, a saber, 'negativa e prestacional'. A função negativa relaciona o Estado e às demais pessoas (coletiva ou singularmente considerada), que repousa na capacidade de autodeterminação, jungida pelo ideário de liberdade e considerada como a possibilidade do indivíduo governar a si mesmo. Por sua vez, a acepção prestacional tem seus alicerces calcados na necessidade de prestação e tutela pelo Estado da dignidade da pessoa. A dimensão prestacional pode ser considerada mesmo quando em relação à primeira, pois, na ausência daquela, por motivos transitórios (como pode ocorrer no caso de cirurgias e internações por motivos médicos) ou permanentes, poderá ocorrer a perda da capacidade de autodeterminação, mas a pessoa continua com o direito de ser protegida em sua dignidade.

Schaefer (2006) acrescenta que a dignidade humana possui duas dimensões que lhe são constitutivas: uma negativa, significando que a pessoa não pode ser reduzida a alvo de ofensas e humilhações; e uma positiva, no sentido de que a pessoa deve ter plena 
possibilidade de autodeterminação. A doutrina admite a concepção pela qual haverá necessidade de proteção da dignidade humana sempre que a pessoa for reduzida em sua condição humana ou sempre que for rebaixada a objeto, "a mero instrumento, tratada como uma coisa, em outras palavras, sempre que a pessoa venha a ser descaracterizada e desconsiderada como sujeito de direitos" (SARLET, 2007, p. 98). Partindo desse pressuposto, tem-se preceituado (MORAES, 2003) que o 'substrato material da dignidade' se apresenta fundamentado em quatro postulados: Liberdade; Igualdade; Integridade psicofísica e Solidariedade.

O termo liberdade segundo o Dicionário da Língua Portuguesa (NASCENTES, 1988) significa: "faculdade de fazer ou deixar de fazer uma coisa por vontade própria sem se submeter a imposições alheias; condição de homem livre, não pertencente a nenhum senhor; gozo dos direitos de homem livre".

Por esse conceito é fácil perceber que a dignidade humana somente pode existir se o homem for livre, capaz de ter e exercer direitos com possibilidade de escolha. Como já afirmou Sarmento (2006, p. 221), "os particulares são titulares de uma esfera de liberdade juridicamente protegida, que deriva do reconhecimento de sua dignidade", a liberdade, encontra uma concepção dualista na autonomia privada e como soberania popular. A primeira significando a chamada liberdade dos modernos, com inspiração no modelo liberal, e a última na chamada liberdade dos antigos, formulada na acepção da 'polis' grega. Concepção que encontra seus paradigmas nas liberdades individuais e na soberania popular.

Sarmento(2006) ainda faz referência às chamadas liberdade positiva e negativa. Esta se relaciona à possibilidade do indivíduo de agir ou não de acordo com a sua subjetividade e sem elementos coativos externos. É a liberdade com ausência de constrangimento. Já a liberdade positiva seria aquela em que a pessoa tem o direito de se orientar segundo a sua vontade e, por isso, está relacionada à autodeterminação (FREIRE DE SÁ, 2003). É a liberdade onde a pessoa reúne as condições para agir sem depender de fatores externos.

Como se sabe a opressão não vem apenas do Estado, pois o Poder está espalhado por toda a sociedade, de forma que também as relações entre particulares podem oprimir e cercear a liberdade da pessoa. Razão pela qual a liberdade deve ser vista sob o ponto de vista da pessoa humana e não do Estado. Assim é fato perceber que a pessoa para se desenvolver e ser concebida como sujeito de direito precisa ter liberdade tanto em suas relações com o estado (autonomia pública do cidadão) como nas relações interprivadas (autonomia privada). Nesse sentido Moraes (2003, p. 95) entende que o princípio da liberdade individual "significa, hoje, poder realizar, sem interferências de qualquer gênero, as próprias escolhas individuais, 
exercendo-as como melhor lhe convier”. Esse princípio pode ser encontrado no inciso do II do art. $5^{\circ}$ da Constituição da República Federativa do Brasil de 1988, no qual é estabelecido que "ninguém será obrigado a fazer ou deixar de fazer alguma coisa senão em virtude da lei".

Assim, a liberdade tem como consectário lógico a autonomia privada (JUNGES, 2007) que busca significar o poder da pessoa se autodeterminar, de decidir segundo a sua própria vontade. Autonomia considerada como elemento essencial da dignidade da pessoa humana baseada na crença do "indivíduo conformador de si próprio e da sua vida"(SARMENTO, 2006, p. 46). A autonomia privada dessa forma é considerada como instrumento de realização do princípio da liberdade (VIEIRA, 2001) e, consequentemente, da própria dignidade da pessoa humana, vez que negar ao homem o poder de decidir o modo pelo qual vai conduzir a sua vida privada é frustrar sua possibilidade de realização existencial.

Todavia, a autonomia privada necessita de um ambiente propício para que possa se concretizar, posto que sem igualdade (ROCHA, 2004) de condições, não há liberdade e muito menos respeito à dignidade da pessoa humana.

A Constituição da República Federativa do Brasil de 1988 reconhece essa necessidade de igualar as condições, além de reconhecer a obrigação do Estado (SARMENTO, 2006) de agir com a finalidade de colocar as partes em igualdade de condições. E não é só isso: a Constituição, ao reconhecer a autonomia privada, o fez em diferentes níveis, conferindo evidentemente mais força às questões da autonomia que dizem respeito à pessoa humana fonte de sua dignidade - e menos força nas questões relacionadas ao patrimônio.

Trata-se, como já afirmou Perlingieri (2007), de uma questão de fundamento da autonomia, vez que não se pode conferir igual proteção à autonomia negocial (STEINMETZ, 2007) e à autonomia nas questões existenciais que dão direto na sua dignidade como pessoa humana. Existe uma hierarquia muito maior no fundamento da autonomia nas questões da pessoa em relação à autonomia negocial.

No Estado Contemporâneo (SARMENTO, 2008) com a evolução do Direito Constitucional sobre o tema da dignidade da pessoa e o reconhecimento dos Direitos Fundamentais o foco da autonomia, sem que se desconsidere o direito de decidir sobre seu patrimônio, passa a ser as questões e escolhas existenciais da pessoa, de dizer qual a sua orientação religiosa, sexual, política, entre outras. Tal autonomia da pessoa possibilita de um lado o direito de escolha sobre os rumos, concepções e modos de vida, o que pode e deve ser respeitado pelo Estado, vez que não cabe ao Estado decidir como a pessoa conduzirá a sua própria vida e, de outro lado, figura como um limitador da vontade, posto que a autonomia da pessoa se limita aos ditames legais, sendo conformada a preceitos éticos, jurídicos e legais. 
Cabe a pessoa fazer as suas escolhas, optar pelo seu modo de vida, segundo as suas crenças e viver de acordo com elas, desde que não lese os direitos de outras pessoas, "fundamento e legitimação de sujeitos livres e iguais" (RÜGER e RODRIGUES, 2007, p. 10). Evolui-se da autonomia da vontade (Estado Liberal Burguês) para a autonomia privada (Estado Contemporâneo) como uma releitura da primeira, posto que essa última se aproxima mais das modificações do sistema jurídico e da transformações constitucionais contemporâneas que norteiam o homem como fim de todas as coisas e que vinculam a autonomia ao poder de criar regras jurídicas dentro dos limites legais (FARIA, 2007).

\section{MÉTODOS DE PESQUISA}

\subsection{ENQUADRAMENTO METODOLÓGICO}

Os delineamentos desta pesquisa deram-se em função dos objetivos, dos procedimentos e da abordagem do problema. No que concerne aos objetivos, esta pesquisa consiste de um estudo do tipo exploratório e descritivo. Tendo em vista o problema de pesquisa construído e considerando os objetivos deste trabalho, a pesquisa se caracteriza como exploratória pelo fato de ter como intuito a busca de maior conhecimento sobre o tema - regulação jurídica do setor tabagista. Para Cervo e Bervian (1996), o estudo exploratório é responsável por observar, registrar, analisar e correlacionar os fatos ou fenômenos sem manipulá-los. A presente pesquisa também caracteriza-se como descritiva quanto aos objetivos, uma vez que focaliza descrever a regulamentação jurídica do setor tabagista, especialmente com relação às normas da ANVISA que cuidam da matéria relativa à presença de nicotina nos produtos derivados de tabaco. Para Gil (2009) a pesquisa descritiva tem como objetivo primordial a descrição das características de determinada população ou fenômeno ou o estabelecimento de relações entre variáveis.

Quanto aos procedimentos, a pesquisa caracteriza-se como bibliográfica e documental. Conforme Gil (2009), a pesquisa bibliográfica pode ser desenvolvida a partir de material já elaborado, constituído principalmente de livros e artigos científicos e a pesquisa documental, por valer-se de materiais que não receberam um tratamento analítico, ou que ainda podem ser reelaborados de acordo com os objetivos.

\subsection{PROCEDIMENTOS PARA COLETA E ANÁLISE DE DADOS}

Optou-se pela presente análise em decorrência da disposição prevista no inciso XII, do art. 24 da Constituição da República Federativa do Brasil de 1988, e da Lei 9.782, de 26 de 
janeiro de 1999, que criou a Agência Nacional da Vigilância Sanitária - ANVISA, agência reguladora com independência administrativa, que incorporou as competências da antiga Secretaria de Vigilância Sanitária do Ministério da Saúde, que, conforme o art. 6º, tem “por finalidade institucional promover a proteção da saúde da população, por intermédio do controle sanitário da produção e da comercialização de produtos e serviços submetidos à vigilância sanitária".

$\mathrm{Na}$ apuração dos dados fez-se uma pesquisa bibliográfica sobre o tema com a finalidade de verificar o Estado da Arte, após foram coletadas informações, por meio de uma pesquisa documental, nas normas da ANVISA. Na coleta dos dados utilizou-se como critério de busca os descritores: "tabaco", "tabagismo", "cigarro" e "nicotina".

Em síntese, a pesquisa classifica-se como exploratória e descritiva, utilizando como procedimento a pesquisa bibliográfica e documental.

\section{DISCUSSÃO DE RESULTADOS}

Examinando as normas editadas pela ANVISA foram separadas e examinadas as resoluções estruturadas na tabela 2 .

\begin{tabular}{|c|c|}
\hline Norma & Ementa \\
\hline $\begin{array}{l}\text { Resolução RDC no } 46 \\
\text { de } 28 \text { de agosto de } \\
2009\end{array}$ & $\begin{array}{l}\text { Proíbe a comercialização, importação e propaganda de quaisquer } \\
\text { dispositivos eletrônicos para fumar, conhecidos com cigarro } \\
\text { eletrônico. }\end{array}$ \\
\hline $\begin{array}{l}\text { Resolução RDC no } 32 \\
\text { de } 29 \text { de maio de } 2008\end{array}$ & $\begin{array}{l}\text { Altera dispositivos da Resolução - RDC } 90 \text {, de } 27 \text { de dezembro de } \\
\text { 2007, que dispõe sobre o registro de dados cadastrais dos produtos } \\
\text { fumígenos derivados do tabaco. }\end{array}$ \\
\hline $\begin{array}{l}\text { Resolução RDC n }{ }^{\circ} 54 \\
\text { de } 06 \text { de agosto de } \\
2008\end{array}$ & $\begin{array}{l}\text { Introduz novas imagens e frases de advertência nas embalagens e } \\
\text { materiais de propaganda dos produtos fumígenos. }\end{array}$ \\
\hline $\begin{array}{l}\text { Resolução RDC n }{ }^{\circ} 10 \\
\text { de } 18 \text { de junho de } 2008\end{array}$ & $\begin{array}{l}\text { Altera as Resoluções RDC n⿳3335, de } 2003 \text {, e RDC } 86 \text { de } 2006 \text {, que } \\
\text { dispõem sobre embalagens de cigarros. }\end{array}$ \\
\hline $\begin{array}{l}\text { Resolução RDC no } 86 \\
\text { de } 29 \text { de maio de } 2008\end{array}$ & $\begin{array}{l}\text { Altera a RDC } 335 \text {, de } 21 \text { de Novembro de } 2003 \text {. Dispõe sobre a } \\
\text { logo-marca e o Disque-Saúde nas embalagens de produtos } \\
\text { fumígenos. }\end{array}$ \\
\hline $\begin{array}{l}\text { Resolução RDC n }{ }^{\circ} 90 \\
\text { de } 27 \text { de dezembro de } \\
2007\end{array}$ & $\begin{array}{l}\text { Dispõe sobre o registro de dados cadastrais dos produtos fumígenos } \\
\text { de derivados do tabaco }\end{array}$ \\
\hline $\begin{array}{l}\text { Resolução RDC n } 86, \\
\text { de } 17 \text { de maio de } 2006\end{array}$ & Altera a RDC 335 de 21 de Novembro de 2003 \\
\hline $\begin{array}{l}\text { Resolução RDC n }{ }^{\circ} 168 \text {, } \\
\text { de } 08 \text { de julho de } 2004\end{array}$ & $\begin{array}{l}\text { Altera Resolução RDC no } 335 \text {, de } 21 \text { de novembro de 2003. Aterá } \\
\text { prazos da RDC 335/2003. }\end{array}$ \\
\hline Resolução - RDC n ${ }^{\circ}$ & Regulamenta as embalagens e materiais de propaganda dos \\
\hline
\end{tabular}




\begin{tabular}{|c|c|}
\hline $\begin{array}{l}335, \text { de } 21 \text { de } \\
\text { novembro de } 2003\end{array}$ & produtos fumígenos. \\
\hline $\begin{array}{l}\text { Resolução RDC no } 199 \text {, } \\
\text { de } 24 \text { de julho de } 2003\end{array}$ & $\begin{array}{l}\text { Regulamenta a Lei } \mathrm{n}^{\circ} 10.702 \text { de } 2003 \text {, sobre as frases de } \\
\text { advertência do Ministério da Saúde exibidas durante a transmissão } \\
\text { no país de eventos esportivos e culturais internacionais. }\end{array}$ \\
\hline $\begin{array}{l}\text { Resolução RDC n }{ }^{\circ} 15 \\
\text { de } 17 \text { de janeiro de } \\
2003\end{array}$ & $\begin{array}{l}\text { Regulamenta disposições dadas pela Lei n. }{ }^{\circ} 9.294 \text { de } 15 \text { de julho de } \\
\text { 1996, quanto à propaganda e pontos de venda e proíbe a venda de } \\
\text { produtos fumígenos pela internet. }\end{array}$ \\
\hline $\begin{array}{l}\text { Resolução } \mathrm{RDC} \mathrm{n}^{\circ} 304, \\
\text { de } 07 \text { de novembro de } \\
2002\end{array}$ & $\begin{array}{l}\text { Proíbe a produção, importação, comercialização, propaganda e } \\
\text { distribuição de alimentos que simulem produtos fumígenos. }\end{array}$ \\
\hline $\begin{array}{l}\text { Resolução RDC n }{ }^{\circ} 46, \\
\text { de } 28 \text { de março de } 2001\end{array}$ & $\begin{array}{l}\text { Estabelece os teores máximos permitidos de alcatrão, nicotina e } \\
\text { monóxido de carbono presentes na corrente primária da fumaça, } \\
\text { para os cigarros comercializados no Brasil. }\end{array}$ \\
\hline
\end{tabular}

Tabela 2 - Regulamentação de produtos derivados de tabaco pela Agência Nacional de Vigilância Sanitária-ANVISA

Fonte: Elaborado pelo autor

Pode-se verificar que a Resolução RDC n 46, de 28 de março de 2001, da ANVISA, reconhece o aumento expressivo do tabagismo no mundo e que segundo as expectativas, o tabaco, será responsável por 10 milhões de mortes a cada ano até o ano de 2030, e que 70\% dessas mortes ocorreram em países em desenvolvimento, como o Brasil. Para tanto, consente com o reconhecimento mundial pela necessidade do estabelecimento de controle dos teores máximos de alcatrão, nicotina e monóxido de carbono dos cigarros. Outrossim, o art. $1^{\circ}$ da citada resolução, regulamenta que a redução dos mencionados teores será de maneira gradual, até alcançar o índice "máximo de 10 miligramas, 1,0 miligrama e 10 miligramas, respectivamente para os teores de alcatrão, nicotina e monóxido de carbono em cada cigarro". A mesma Resolução também estabelece a vedação de denominação de classes de produtos com expressões como: ultra baixo, baixo teor, suave, light, soft, leve, teor moderado e alto teor. $\mathrm{O}$ art. $3^{\circ}$ determina a obrigação da impressão nas embalagens dos produtos "dos teores de alcatrão, nicotina e monóxido de carbono, acompanhada da seguinte informação adicional: "não existem níveis seguros para consumo destas substâncias"”.

A Resolução RDC no 304, de 07 de novembro de 2002, da ANVISA, visa à necessidade constante de aperfeiçoamento das ações de controle sanitário da área de alimentos objetivando a proteção da saúde das pessoas. E por considerar que o consumo de alimentos com apresentação semelhante a charutos ou cigarros pode promover o consumo do tabaco entre adolescente, veda, no art. $1^{\circ}$, em todo o território nacional "a produção, importação, comercialização, propaganda e distribuição de alimentos com forma de apresentação semelhante a cigarro, charuto, cigarrilha." O art. $2^{\circ}$ proíbe o "uso de embalagens 
de alimentos que simulem ou imitem as embalagens de produtos fumígenos, como cigarros, charutos, cigarrilhas."

A Resolução RDC n 15, de 17 de janeiro de 2003, da ANVISA, por sua vez, traz especificações sobre os tipos de divulgação de produtos de tabaco que são proibidos por força do disposto no $\S 4^{\circ}$ do art. 220, da Constituição da República Federativa do Brasil, de 1988, com a regulamentação dada pela Lei n. 9.294 de 15 de julho de 1996, com as alterações dadas pela Lei n. ${ }^{\circ}$ 10.167, de 27 de dezembro de 2000. A vedação alcança os meios eletrônicos, impresso e outras formas de comunicação ao público direta ou indiretamente.

A Resolução RDC n 199, de 24 de julho de 2003, da ANVISA, cuida da propaganda dos produtos derivados de tabaco, estabelecendo que a eventos patrocinados por empresas do setor tabagista deverão, durante a transmissão, veicular mensagens de advertências sobre os malefícios do fumo.

A Resolução RDC no 335, de 21 de novembro de 2003, da ANVISA, determina no art. $1^{\circ}$ que "todos os produtos fumígenos derivados do tabaco, conterão na embalagem e na propaganda, advertência ao consumidor, sobre os malefícios decorrentes do uso destes produtos." Também estabelece que as advertências serão acompanhadas de imagens, que devem ser impressas em toda a extensão da maior face visível ao consumidor. Determina ainda que "a impressão nas embalagens de cigarros dos teores de alcatrão, nicotina e monóxido de carbono presentes na corrente primária é facultativa à empresa". $\mathrm{O}$ art. $8^{\circ}$ estabelece que nas embalagens deverá ser impresso a seguinte advertência: "Este produto contem mais de 4.700 substâncias tóxicas, e nicotina que causa dependência física ou psíquica. Não existem níveis seguros para consumo destas substâncias". Também determina a impressão da seguinte frase: "Venda proibida a menores de 18 anos - Lei 8.069/1990 e Lei 10.702/2003".

A Resolução RDC n ${ }^{\circ} 168$, de 08 de julho de 2004, da ANVISA, altera prazos fixados pela Resolução RDC no 335, de 21 de novembro de 2003, sem lhe alterar o teor.

Resolução RDC n 86 , de 17 de maio de 2006, da ANVISA, altera a redação do art. $3^{\circ}$ da Resolução RDC n 335, de 21 de novembro de 2003, que cuida das advertências a serem impressas nas embalagens e altera prazos da mesma resolução.

A Resolução RDC n 90, de 27 de dezembro de 2007, da ANVISA, dispõe sobre o registro de dados cadastrais dos produtos fumígenos derivados do tabaco. Determina no art. $3^{\circ}$ que "é obrigatório o registro dos dados cadastrais de todas as marcas de produtos fumígenos derivados do tabaco, fabricadas no território nacional, importadas ou exportadas." 
A Resolução RDC n 86, de 29 de maio de 2008 e a Resolução RDC nº 10, de 18 de junho de 2008, ambas da ANVISA, alteram a redação do art. $3^{\circ}$ da Resolução $\operatorname{RDC} n^{\circ} 335$, de 21 de novembro de 2003, que cuida das advertências a serem impressas nas embalagens e alteram prazos da mesma resolução

A Resolução RDC n ${ }^{\circ}$ 54, de 06 de agosto de 2008, da ANVISA, altera a redação do art. $2^{\circ}$ da Resolução RDC no 335, de 21 de novembro de 2003, que cuida das advertências e imagens que devem ser veiculadas nas embalagens de cigarro e altera prazos da mesma resolução.

A Resolução RDC n 32, de 29 de maio de 2008 e a Resolução RDC n 46, de 28 de agosto de 2009, ambas da ANVISA, tratam, respectivamente, do registro de dados cadastrais das fornecedoras de tabaco e da proibição do dispositivo eletrônico para fumar, também chamado de cigarro eletrônico.

Não foram encontradas normas que vedação a adição de substância como a amônia cuja finalidade é aumentar a liberação do teor de nicotina no organismo, bem como não se encontrou vedação da presença da própria nicotina.

Outras resoluções da ANVISA, não relacionadas ao tabaco, trazem importantes orientações, pois, embora, a ANVISA reconheça o poder viciogênico da nicotina não insere a mesma como substância controlada, no rol de psicotrópicos, vez que a Resolução RDC n. ${ }^{\circ}$ 228, de 11 de dezembro de 2001, não faz nenhuma menção a mesma. A Resolução RDC n ${ }^{\circ}$ 360, de 23 de dezembro de 2003, da ANVISA, embora não cuide da regulamentação do Tabaco, determina a obrigatoriedade da rotulagem em alimentos por considerar a necessidade “do constante aperfeiçoamento das ações de controle sanitário na área de alimentos visando a proteção à saúde da população". Na mesma linha de justificativa a mencionada Resolução entende que a rotulagem facilita "a informação que se declara na rotulagem nutricional complementa as estratégias e políticas de saúde dos países em benefício da saúde do consumidor". A Resolução RDC n 140, de 29 de maio de 2003, determina a necessidade de que todos os medicamentos tenham bula, vez que a bula para o paciente tem o objetivo de servir de "documento legal sanitário que contém informações técnicocientíficas e orientadoras sobre medicamentos, as quais são disponibilizadas aos usuários em linguagem apropriada.", evidenciando o direito a informação que goza o usuário.

\section{CONSIDERAÇÕES FINAIS}

O sistema constitucional atribui uma função complexa ao Estado exigindo a sua atuação em determinadas situações e obrigando sua não intervenção em outras, vista a 
eficácia vinculativa da norma que se destina ao Estado. Outrossim, atribui-se ao Estado, na proteção da pessoa, uma dupla dimensão: negativa e prestacional. A função negativa relaciona o Estado e às demais pessoas (coletiva ou singularmente considerada), que repousa na capacidade de autodeterminação, jungida pelo ideário de liberdade e considerada como a possibilidade do indivíduo governar a si mesmo. Por sua vez, a acepção prestacional tem seus alicerces calcados na necessidade de prestação e tutela pelo Estado da dignidade da pessoa. A dimensão prestacional vincula a ação estatal mesmo quando ocorrer à perda da capacidade de autodeterminação, pois ainda assim a pessoa continua com o direito de ser protegida em sua dignidade.

Na regulamentação pela ANVISA do setor tabagista vê-se que não há norma impedindo a presença de nicotina nos produtos derivados de tabaco, embora, haja reconhecimento do seu poder viciogênico conforme disposto na Resolução $\operatorname{RDC}^{\circ} 335$, de 21 de novembro de 2003. Por outro lado, há contradição na forma pela qual a ANVISA aborda a questão, pois a Resolução RDC n 46, de 28 de março de 2001 que estabelece o nível máximo de 1,0 miligrama de nicotina em cada cigarro, também determina a indicação na embalagem do produto de que: "não existem níveis seguros para consumo destas substâncias". Ora, se não existe limite seguro, como e com que parâmetro a ANVISA fixa o limite de 1,0 miligrama de nicotina em cada cigarro? Outra contradição que se mostra evidente se liga ao fato da Resolução RDC n 46, de 28 de março de 2001, determinar teores máximos de nicotina, mas não proibir a adição de substâncias, como a amônia, que tem a função de liberar mais nicotina no organismo da pessoa, aumentando a dependência.

Situação que se repete na Resolução RDC no 335, de 21 de novembro de 2003, que determina a impressão da embalagem de cigarro da seguinte expressão: "Este produto contem mais de 4.700 substâncias tóxicas, e nicotina que causa dependência física ou psíquica. Não existem níveis seguros para consumo destas substâncias". Mais uma vez se verifica a contradição, pois se não há nível seguro a ANVISA admite a circulação de um produto com efeitos reconhecidamente deletérios a pessoa. Ainda a mesma resolução admite que a nicotina causa dependência física e psíquica, entretanto, não a inclui no rol de substâncias psicotrópicas da Resolução RDC n. ${ }^{\circ}$ 228, de 11 de dezembro de 2001, criando uma situação onde de fato a nicotina é um psicotrópico, posto que geradora de dependência, mas juridicamente ela não é assim rotulada vez que o Estado não a inclui na listagem daquelas substâncias.

A síntese das resoluções da ANVISA demonstra que há uma preocupação em advertir o consumidor sobre os perigos do fumo, entretanto, essa advertência é tímida e pouco clara, 
pois menciona uma dentre mais de 4700 substâncias que estão presente no cigarro. Fazendo um paralelo com outros produtos como alimentos e medicamentos, que na maioria das vezes não vão gerar a dependência reconhecidamente causada pela nicotina, há a obrigações de informações nutricionais no caso de alimentos e da bula no caso dos medicamentos, sempre com o objetivo de garantir o direito de informação ao consumidor e resguardar a saúde pública. O que não ocorre no caso do cigarro e que torna premente a necessidade de uma maior informação sobre as substâncias que compõe o produto, pois somente assim poderá se falar de informações claras ao consumidor, somente assim poderá o consumidor, uma vez informado, exercer de forma consciente a sua autonomia e optar por fumar ou não. Atualmente, sem informação clara o usuário se torna refém pela ignorância sobre o produto, e, uma vez iniciado o uso do cigarro se mantém refém pela dependência a nicotina. Essa situação impede o exercício da autonomia pela ignorância nos atos iniciais do uso do tabaco, bem como impossibilita a possibilidade de parar de fumar devido a dependência, mitigando a autonomia privada. Outrossim, a situação mostra a necessidade de instruir as pessoas sobre a composição do cigarro por meio de da inserção de maiores informações o que pode ser alcançado por meio de uma bula, a semelhança do que ocorre nos medicamentos, nas embalagens de cigarro.

O Estado contemporâneo há uma constante mitigação da autonomia privada em razão da 'supremacia do interesse público sobre o particular'. Isso ocorre diuturnamente em nosso dia-a-dia com a obrigação de pagarmos impostos, de termos autorização para dirigir veiculo automotor, na imposição de limites de velocidade para o trânsito de veículos, na necessidade de alvará para comercializar, na obrigatoriedade do uso de cinto de segurança, entre várias outras situações. A tônica é que se abre mão da autonomia privada em razão de um bem maior coletivo. No caso do cigarro, entretanto, a situação se inverte, pois aqui se admite que o indivíduo tem plena consciência do que faz, e que o interesse individual, focado no respeito à autonomia privada, deve prevalecer sobre a relevância social, mesmo que esse interesse individual seja baseado na ignorância sobre o danos causados a própria pessoa e a coletividade, vez que o tabagismo é também um problema de saúde pública.

Outrossim, percebe-se que a atuação do Estado na regulamentação do setor tabagista se restringe ao reconhecimento dos danos causados pelo tabaco sem que, no entanto, tome providências para garantir condições para que pessoa possa, de forma consciente, exercer a sua autonomia. 


\begin{abstract}
Autonomy is a stalemate on the issue of choice of tobacco use and regulation by the state. This study examines state action, post CRFB/88 through ANVISA in regulating the presence of nicotine in tobacco products. This is an exploratory and descriptive, with bibliographical and documentary procedures. Cigarettes have more than 4720 substances, such is the nicotine that causes addiction. The state action is limited to recognition of the damage caused by tobacco. There were no rules that deny the presence of nicotine in cigarettes.
\end{abstract}

Keywords: Private autonomy; Nicotine, ANVISA, Acting State.

\title{
REFERÊNCIAS
}

AGÊNCIA NACIONAL DE VIGILÂNCIA SANITÁRIA. Resolução RDC no 46, de 28 de agosto de 2009. Proíbe a comercialização, importação e propaganda de quaisquer dispositivos eletrônicos para fumar, conhecidos com cigarro eletrônico. D.O.U. Diário Oficial da União; Poder Executivo, nº 166, de 31 de agosto de 2009, seção 1, pág. 45.

AGÊNCIA NACIONAL DE VIGILÂNCIA SANITÁRIA. Resolução RDC n 90, de 27 de dezembro de 2007. Dispõe sobre o registro de dados cadastrais dos produtos fumígenos de derivados do tabaco. Republicada por ter saído, publicado no DOU no- 249, de 28-12-07, Seção 1, página 115, com incorreção no original.

AGÊNCIA NACIONAL DE VIGILÂNCIA SANITÁRIA. Resolução RDC no 32, de 29 de maio de 2008. Altera dispositivos da Resolução - RDC 90, de 27 de dezembro de 2007, que dispõe sobre o registro de dados cadastrais dos produtos fumígenos derivados do tabaco.

D.O.U. - Diário Oficial da União; Poder Executivo, de 30 de maio de 2008.

AGÊNCIA NACIONAL DE VIGILÂNCIA SANITÁRIA. Resolução - RDC no 335, de 21 de novembro de 2003. Regulamenta as embalagens e materiais de propaganda dos produtos fumígenos. D.O.U. - Diário Oficial da União; Poder Executivo, de 24 /11/2003

AGÊNCIA NACIONAL DE VIGILÂNCIA SANITÁRIA. Resolução RDC n 54, de 06 de agosto de 2008. Introduz novas imagens e frases de advertência nas embalagens e materiais de propaganda dos produtos fumígenos. D.O.U. - Diário Oficial da União; Poder Executivo, de 07/08/08 p.48, seção 1 n 151 .

AGÊNCIA NACIONAL DE VIGILÂNCIA SANITÁRIA. Resolução RDC no $\mathbf{1 0}$, de 18 de junho de 2008. Altera as Resoluções RDC n³35, de 2003, e RDC 86 de 2006, que dispõem sobre embalagens de cigarros. D.O.U. - Diário Oficial da União; Poder Executivo, de 16 de fevereiro de 2007

AGÊNCIA NACIONAL DE VIGILÂNCIA SANITÁRIA. Resolução RDC n 86, de 29 de maio de 2008. Altera a RDC 335, de 21 de Novembro de 2003. Dispõe sobre a logo-marca e o Disque-Saúde nas embalagens de produtos fumígenos. D.O.U. - Diário Oficial da União; Poder Executivo, de 24 de maio de 2006.

AGÊNCIA NACIONAL DE VIGILÂNCIA SANITÁRIA. Resolução RDC no 168, de 08 de julho de 2004. Altera Resolução RDC $n^{\circ} 335$, de 21 de novembro de 2003. Aterá prazos da RDC 335/2003. D.O.U. - Diário Oficial da União; Poder Executivo, de 09 de julho de 2004 
AGÊNCIA NACIONAL DE VIGILÂNCIA SANITÁRIA. Resolução RDC n 199, de 24 de julho de 2003. Regulamenta a Lei $n^{\circ} 10.702$ de 2003, sobre as frases de advertência do Ministério da Saúde exibidas durante a transmissão no país de eventos esportivos e culturais internacionais. D.O.U. - Diário Oficial da União; Poder Executivo, de 28/07/2003.

AGÊNCIA NACIONAL DE VIGILÂNCIA SANITÁRIA. Resolução RDC no 15, de 17 de janeiro de 2003. Regulamenta disposições dadas pela Lei n. ${ }^{\circ} 9.294$ de 15 de julho de 1996, quanto à propaganda e pontos de venda e proíbe a venda de produtos fumígenos pela internet. D.O.U. - Diário Oficial da União; Poder Executivo, de 20 de janeiro de 2003

AGÊNCIA NACIONAL DE VIGILÂNCIA SANITÁRIA. Resolução RDC no 304, de 07 de novembro de 2002. Proíbe a produção, importação, comercialização, propaganda e distribuição de alimentos que simulem produtos fumígenos. D.O.U. - Diário Oficial da União; Poder Executivo, de 08 de novembro de 2002.

AGÊNCIA NACIONAL DE VIGILÂNCIA SANITÁRIA. Resolução RDC no 86, de 17 de maio de 2006. Altera a RDC 335 de 21 de Novembro de 2003. D.O.U. - Diário Oficial da União; Poder Executivo, de 24 de maio de 2006.

AGÊNCIA NACIONAL DE VIGILÂNCIA SANITÁRIA. Resolução RDC no 46, de 28 de março de 2001. Estabelece os teores máximos permitidos de alcatrão, nicotina e monóxido de carbono presentes na corrente primária da fumaça, para os cigarros comercializados no Brasil.

AGÊNCIA NACIONAL DE VIGILÂNCIA SANITÁRIA. Resolução RDC no 140, de 29 de maio de 2003 DOU 02/06/03 Texto de retificação: Republicada, no dia 24 de setembro de 2003, por ter saído com incorreção no original, publicado no DOU n ${ }^{\circ} 104$, de 2 de junho de 2003, Seção 1, pág.39.

AGÊNCIA NACIONAL DE VIGILÂNCIA SANITÁRIA. Resolução RDC n. ${ }^{\circ} 228$, de 11 de dezembro de 2001. Atualização das listas de substâncias sujeitas a controle especial.

AGÊNCIA NACIONAL DE VIGILÂNCIA SANITÁRIA. Resolução - RDC no 360, de 23 de dezembro de 2003. Diário Oficial da União, D.O.U, Poder Executivo, de 26/12/2003, Aprova Regulamento Técnico Sobre Rotulagem Nutricional de Alimentos Embalados

AGÊNCIA NACIONAL DE VIGILÂNCIA SANITÁRIA - ANVISA. Registro de Produto Fumígeno - Dados cadastrais. Relação de marcas de cigarros - ano 2010. Disponível em http://portal.anvisa.gov.br/wps/wcm/connect/30d50a0040f500728641fe8ce3172c3d/Marcas+ de+Cigarros_2010-08-30.pdf?MOD=AJPERES\&useDefaultText=0\&useDefaultDesc. Acesso em 13 de setembro de 2010

ARENDT, Hannah. A condição humana. 10. ed. Rio de Janeiro: Forense Universitária, 2008.

BRASIL, Constituição da República Federativa do Brasil. 05 de outubro de 1988.

BRASIL, Lei no 9.782, de 26 de janeiro de 1999. Define o Sistema Nacional de Vigilância Sanitária, cria a Agência Nacional de Vigilância Sanitária, e dá outras providências.

CERVO, A.; BERVIAN, A. Metodologia científica: para uso dos estudantes universitários. 4. ed. São Paulo: McGraw-Hill do Brasil, 1996. 
CLÈVE, Clèmerson Merlin. A eficácia dos direitos fundamentais sociais. Revista Crítica Jurídica, $\mathrm{n}^{\circ} .22$, jul/dez 2003. Disponível em: 〈www.juridicas.unam.mx>. Acesso em: 09 mar. 2009.

COMPARATO, Fábio Konder. A afirmação histórica dos direitos humanos. São Paulo: Saraiva, 2001.

COMPARATO, Fábio Konder. Fundamento dos Direitos Humanos. Disponível em: <www.iea.com.br>. Acesso em: 12 dez. 2008.

DELFINO, Lúcio. Responsabilidade civil e tabagismo no Código de Defesa do Consumidor. Belo Horizonte: Del Rey, 2002.

DELFINO, Lúcio. A responsabilidade civil das indústrias fumígenas sob a ótica do Código de Defesa do Consumidor. Revista de Direito do Consumidor. N. ${ }^{\circ}$ 51, ano 13 , jul/set, 2004. São Paulo: RT, 2004.

FARIA, Roberta Elzy Simiqueli de. Autonomia da vontade e autonomia privada. Direito Civil: da autonomia privada nas situações jurídicas patrimoniais e existências.

Atualidades II. Belo Horizonte: Del Rey, 2007.

FREIRE DE SÁ, Maria de Fátima. Biodireito e direito ao próprio corpo. Belo Horizonte: Del Rey, 2003.

GIL, A C. Métodos e Técnicas de Pesquisa Social. 6 ed. 2. Reimpressão. São Paulo: Atlas, 2009.

INSTITUTO BRASILEIRO DE GEOGRAFIA E ESTATÍSTICA - IBGE. Pesquisa Nacional por Amostra de Domicílios: Tabagismo, 2008. Rio de Janeiro: IBGE, 2009.

JUNGES. José Roque. Exigências éticas do consentimento informado. Revista Bioética, v. 15, nº 1, Brasília, Conselho Federal de Medicina, 2007.

KANT, Immanuel. Crítica da Razão Prática. Coleção a obra-prima de cada autor. São Paulo: Martin Claret, 2005.

MARQUES FILHO, José. Comportamento Ético na Prática Médica: de Hipócrates à Bioética. A ética e os reumatologistas. São Paulo: ETCetera Editora de Livros e Revistas, 2004.

MORAES, Alexandre de. Direitos humanos fundamentais: teoria geral, comentários aos arts. $1^{\circ}$ a $5^{\circ}$ da Constituição da República Federativa do Brasil, doutrina e jurisprudência. São Paulo: Atlas, 2007.

MORAES, Maria Celina Bodin. Danos à pessoa humana: uma leitura civil-constitucional dos danos morais. Rio de Janeiro, Renovar, 2003.

NATIONAL INSTITUTE ON DRUG ABUSE - NIDA. U.S. Department of Health and Human Services. Tobacco Addiction. NIH Publication Number 09-4342. June 2009.

Disponível em: http://drugabuse.gov/researchreports/nicotine/nicotine.html. Acesso em 02/09/2010. 
NATIONAL INSTITUTE ON DRUG ABUSE - NIDA. U.S. Department of Health and Human Services. Tobacco Addiction. NIH Publication Number 09-4342. June 2009. Acesso em 02/09/2010, disponível em http://drugabuse.gov/researchreports/nicotine/nicotine.html

PERLINGIERI, Pietro. Perfis do Direito Civil: Introdução ao Direito Civil Constitucional. $3^{\mathrm{a}}$ ed. Rio de Janeiro, Renovar, 2007.

ROCHA, Cármen Lúcia Antunes. Vida Digna: Direito, Ética e Ciência. Os novos domínios científicos e seus reflexos jurídicos. O Direito à vida digna. Belo Horizonte: Fórum, 2004.

ROSEMBERG, José. Nicotina: Droga Universal. São Paulo: SES/CVE, 2003.

RÜGER, André. RODRIGUES, Renata de Lima. Autonomia como princípio jurídico estrutural. Direito Civil: da autonomia privada nas situações jurídicas patrimoniais e existências. Atualidades II. Belo Horizonte: Del Rey, 2007.

SALGADO, R. S. Nicotina: tratando a mais difícil das dependências: o programa "ABRAÇO" de tratamento, em grupo, do tabagismo para profissionais. Belo Horizonte: O lutador, 2002.

SARLET, Ingo Wolfgang. Dignidade da Pessoa Humana e Direitos Fundamentais na Constituição Federal de 1988. Porto Alegre: Livraria do Advogado, 2007.

SARMENTO, Daniel. Os princípios constitucionais da liberdade e da autonomia privada. Os princípios da Constituição de 1988. Rio de Janeiro: Lumen Iuris, 2006.

SARMENTO, Daniel. Direitos Fundamentos e Relações Privadas. $2^{\mathrm{a}}$ Ed. $2^{\mathrm{a}}$ tiragem. Rio de Janeiro: Lumen Iuris, 2008.

SCHAEFER, Fernanda. Responsabilidade Civil dos Planos e Seguros de Saúde. $1^{\mathrm{a}}$. Ed. $4^{\mathrm{a}}$ tiragem. Curitiba: Juruá, 2006.

SILVA, José Afonso da Silva. Poder Constituinte e Poder Popular: estudos sobre a Constituição. 1. ed. 3. tir. São Paulo, Malheiros, 2007.

STEINMETZ, Wilson. Princípio da proporcionalidade e atos de autonomia privada restritivos de direitos fundamentais. Interpretação constitucional. São Paulo: Malheiros, 2007.

VIEIRA, Luzia Chaves. Responsabilidade civil médica e seguro: doutrina jurisprudência. Belo Horizonte: Del Rey, 2001.

WORLD HEALTH ORGANIZATION-WHO. The ICD-10 Classification of Mental and Behavioural Disorders: Clinical descriptions and diagnostic guidelines. Disponível em: http://www.who.int/classifications/icd/en/GRNBOOK.pdf. Acesso em 16 de setembro de 2010. 